\section{Revista Ibero-Americana de Ciências Ambientais}

Ibero-American Journal of Environmental Sciences

Mai $2021-v .12-\mathrm{n} .5$

\title{
Mudanças na qualidade da água em área de intervenção do projeto produtor de água: bacia hidrográfica do rio Camboriú-SC
}

A Bacia Hidrográfica do Rio Camboriú (BHRC) localiza-se no litoral centro-norte do Estado de Santa Catarina. A cada ano o recurso hídrico é mais exigido em função do crescimento demográfico. Diante da crescente necessidade de água, a Agência Nacional de Águas desenvolveu estratégia para colaborar na resolução do problema, falta de água, o Programa Produtor de Água, sua meta principal, aumento da quantidade e qualidade da água em bacias hidrográficas. O presente trabalho analisou a possível mudança na qualidade da água da BHRC entre 2001 a 2017. Para verificar estas possíveis mudanças foram analisados os parâmetros: temperatura, oxigênio dissolvido, condutividade, potencial hidrogeniônico, turbidez, demanda bioquímica de oxigênio, amônio, nitrato, nitrito, fosfato, silício e clorofíla-a. Foram analisados dados de quatro autores para os períodos de 2001/2002; 2005/2206; 2014/2015; $2015 / 2016$ e 2014 a 2017. Foi observado que $67,6 \%$ dos parâmetros analisados apresentaram melhoria na qualidade e $29,4 \%$ permaneceram constantes.

Palavras-chave: Bacia Hidrográfica do Rio Camboriú; Projeto Produtor de Água; Qualidade de Água.

\section{Changes in the water quality in the of intervention area water production project: hydrographic basin of river Camboriú-SC}

The Camboriú River Basin (BHRC) is located on the central-north coast of the State of Santa Catarina. Each year the water resource is more demanded due to population growth. Faced with the growing need for water, the National Water Agency developed a strategy to collaborate in solving the problem, lack of water, the Water Producer Program, its main goal, increasing the quantity and quality of water in river basins. In order to verify these possible changes, the followin parameters were analyzed: temperature, dissolved oxygen, conductivity, hydrogenation potential, turbidity, biochemical demand of oxygen, ammonium, nitrate, nitrite, phosphate, silicon and chlorophyll-a. Data from four authors were analyzed for the 2001/2002 periods; 2005/2206; 2014/2015; 2015/2016 and 2014 to 2017. It was observed that $67.6 \%$ of the parameters analyzed showed improvement in quality and $29.4 \%$ remained constant.

Keywords: Camboriú River Basin; Water Producer Project; Water Quality.

Topic: Desenvolvimento, Sustentabilidade e Meio Ambiente

Reviewed anonymously in the process of blind peer.

Paulo Henrique Santos

Universidade do Vale do Itajaí, Brasil

http://orcid.org/0000-0002-3979-662X

santosph14@yahoo.com.br

Paulo Ricardo Schwingel

Universidade do Vale do Itajaí, Brasil

http://lattes.cnpq.br/5772922139047587

http://orcid.org/0000-0003-2524-9550

schwingel@univali.br
Received: 20/04/2021

Approved: 21/05/2021
Referencing this:

SANTOS, P. H.; SCHWINGEL, P. R.. Mudanças na qualidade da água em área de intervenção do projeto produtor de água: bacia hidrográfica do rio Camboriú-SC. Revista Ibero Americana de Ciências Ambientais, v.12, n.5, p.530-543, 2021. DOI: http://doi.org/10.6008/CBPC2179$\underline{6858.2021 .005 .0042}$ 


\section{INTRODUÇÃO}

A água doce é um recurso natural finito, entretanto sua qualidade tem sido alterada ao longo do tempo, devido ao incremento populacional e ausência de políticas públicas voltadas para a sua preservação. A crescente urbanização e industrialização geram distintas fontes difusas de contaminação, comprometendo a qualidade dos recursos hídricos (TUNDISI et al., 2008). Dados do Fundo das Nações Unidas para a Infância - UNICEF e da Organização Mundial da Saúde - OMS, revelam que quase metade da população mundial não conta com serviço de saneamento básico (BARBOSA, 2015), como consequência disso, a contaminação da água aumenta a cada dia, devido a diferentes tipos de poluentes, como fertilizantes, esgotos, metais pesados ou pesticidas, representando grande problema não apenas no Brasil, mas em todo planeta. Portanto, a qualidade da água é o reflexo do uso e manejo do solo nas bacias hidrográficas.

No Brasil, o Conselho Nacional Meio Ambiente (CONAMA) através da resolução $n^{\circ} 357$ de 20 de março de 2005, é o órgão que caracteriza a qualidade da água dos recursos hídricos (BRASIL, 2005). O Ministério do Meio Ambiente (MMA) criou a Agência Nacional de Águas (ANA), dedicada a fazer cumprir os objetivos e diretrizes da Lei das Águas do Brasil, seguindo quatro linhas de ações: regulação, monitoramento, aplicação da lei e planejamento (ANA, 2018). Em parceria com outras instituições a ANA, vem desenvolvendo o Programa Produtor de Água (PPA), instrumento para a melhoria, recuperação e proteção de recursos hídricos em bacias hidrográficas estratégicas. O PPA é fundamentado em ações executadas no meio rural voltadas à redução da erosão e do assoreamento de mananciais, proporcionando aumento da qualidade e regularidade da oferta de água (ANA, 2008). O PPA utiliza o Pagamento por Serviços Ambientais (PSA) como instrumento de incentivo aos proprietários rurais de forma voluntária nas práticas voltadas a conservação da água e solo.

Nos últimos 15 anos várias experiências têm utilizado o conceito de PSA para tentar manter a qualidade e quantidade dos recursos hídricos no Brasil, entre eles podemos citar, o projeto Conservador das Águas de Extrema/MG, projeto pioneiro no país, o Programa Ecocrédito em Montes Claro (MG), o Projeto Oásis nos Mananciais da Região metropolitana de São Paulo (SP) e outros (ANA, 2012). No Estado de Santa Catarina, vários projetos estão em andamento: Programa de Gestão Ambiental da Região dos Mananciais - SOS Nascentes, município de Joinville; Consórcio Municipal Quiriri, municípios de São Bento do Sul, Rio Negrinho, Corupá e Campo Alegre e o projeto Produtor de Água (PA) na Bacia Hidrográfica do Rio Camboriú (BHRC) (MMA, 2011).

Inspirada pelo PPA, idealizado pela ANA, e por experiências internacionais foi criado o projeto Produtor de Água (PA) na BHRC, com objetivo de garantir a conservação do recurso hídrico, incentivando proprietários rurais a adotarem práticas conservacionistas em suas propriedades. Essas práticas envolvem a recuperação de áreas degradadas, a conservação dos remanescentes florestais nativos, o manejo adequado do solo e a conservação de estradas rurais com o objetivo de aumentar a qualidade e quantidade de água na bacia (KLEMZ et al., 2013).

O MMA (2011) afirma que é necessário o monitoramento dos programas que utilizam a política 
pública PSA, por serem incipientes, muitas vezes não cumprem com seus objetivos, pois não são monitorados de forma adequada, colocando sua credibilidade em dúvida. O projeto PA tem como meta principal o aumento da quantidade e qualidade da água. Estudos realizados por Santos (2018) estabeleceram indicadores de eficácia para os PPA, o indicador qualidade de água obteve $83,9 \%$ de eficácia. O objetivo deste estudo é analisar possíveis mudanças na qualidade da água associada ás áreas de intervenção do projeto Produtor de Água na BHRC.

\section{METODOLOGIA}

A BHRC drena uma área de aproximadamente $200 \mathrm{Km}^{2}$, seu principal rio, o Camboriú, possui cerca de $40 \mathrm{~km}$ de extensão e banha os municípios de Balneário Camboriú e Camboriú (Figura 1). Cerca de 90\% das nascentes que compõem a bacia encontram-se no município de Camboriú (ANTUNES et al., 2007). 0 relevo da bacia é caracterizado por duas unidades: a Serra do Tabuleiro e Planícies litorâneas. A Serra do Tabuleiro distinguisse por encostas íngremes e vales profundos com depósitos sedimentares de sílicoargiloso e areia de quartzos, favorecendo assim o processo de erosão e deslizamento em áreas desmatadas (ANTUNES et al., 2017).
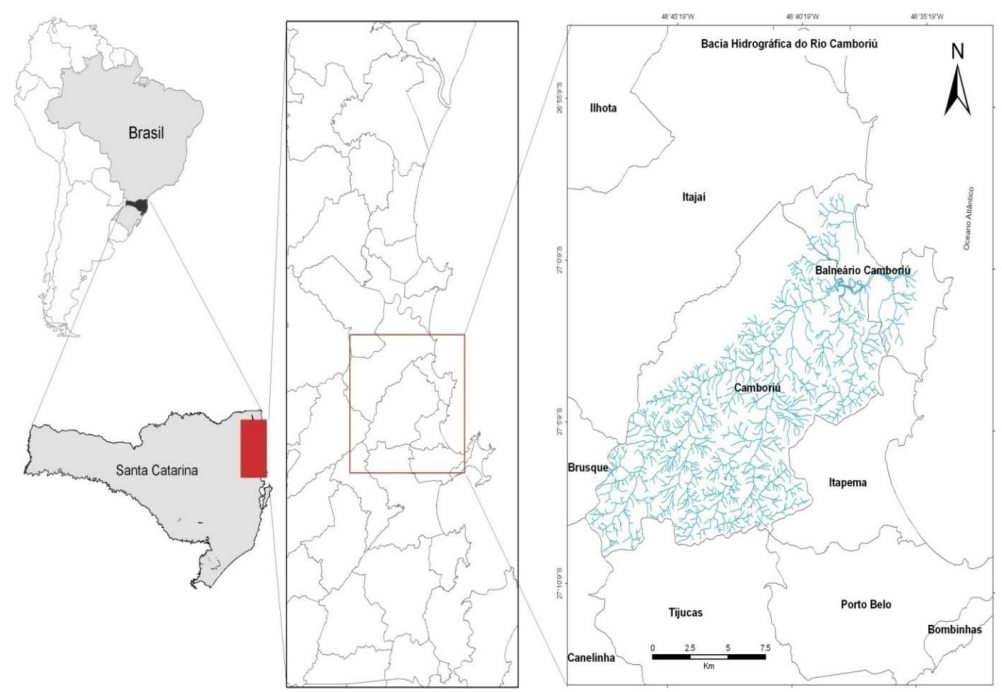

Figura 1: Localização geográfica da Bacia Hidrográfica do Rio Camboriú (SC).

Fonte: EMASA (2009).

O estudo analisou possíveis mudanças físico-químicas e biológicas da água entre os anos de 2001 a 2017, com base nos dados e autores dos períodos de 2001-2002 (URBAN, 2003); 2005-2006 (URBAN, 2008); 2014-2015 (SILVA, 2015); 2015-2016 (RABELO, 2018) e 2014-2017 (EPAGRI, 2017). Com as análises foram verificadas possíveis mudanças na qualidade da água associadas às áreas de intervenções do projeto Produtor de Água, considerando a qualidade da água antes do projeto PA para dados de Urban (2008) e depois do projeto PA dados de Silva (2015) e Rabelo (2018).

Os dados disponibilizados pelos autores e órgãos incluem: condutividade, oxigênio dissolvido, pH, temperatura, turbidez, demanda bioquímica de oxigênio, salinidade, fosfato, amônia, nitrito, nitrato, material particulado, silício e clorofíla-a. A partir do conjunto de dados obtidos, foram estabelecidos dois critérios para escolha dos parâmetros, a saber: apresentar informações antes e depois da criação do 
projeto PA (iniciou com os proprietários rurais em 15 de março 2013), e ter série constante de dados depois da criação do projeto PA. Com base nos critérios foram selecionados os parâmetros: condutividade [mS/c]; $\mathrm{pH}$; temperatura [ ${ }^{\circ} \mathrm{C}$; t turbidez [NTU]; oxigênio dissolvido, demanda bioquímica de oxigênio, amônio, nitrato, nitrito, fosfato, silício em $[\mathrm{mg} / \mathrm{L}]$ e clorofila $[\mu \mathrm{g} / \mathrm{L}]$. Para as análises foram consideradas os dados relativos aos pontos amostrais 3, 5 e 10 (Figura 2). 0 teste estatístico aplicado em cada gráfico foi ANOVA.

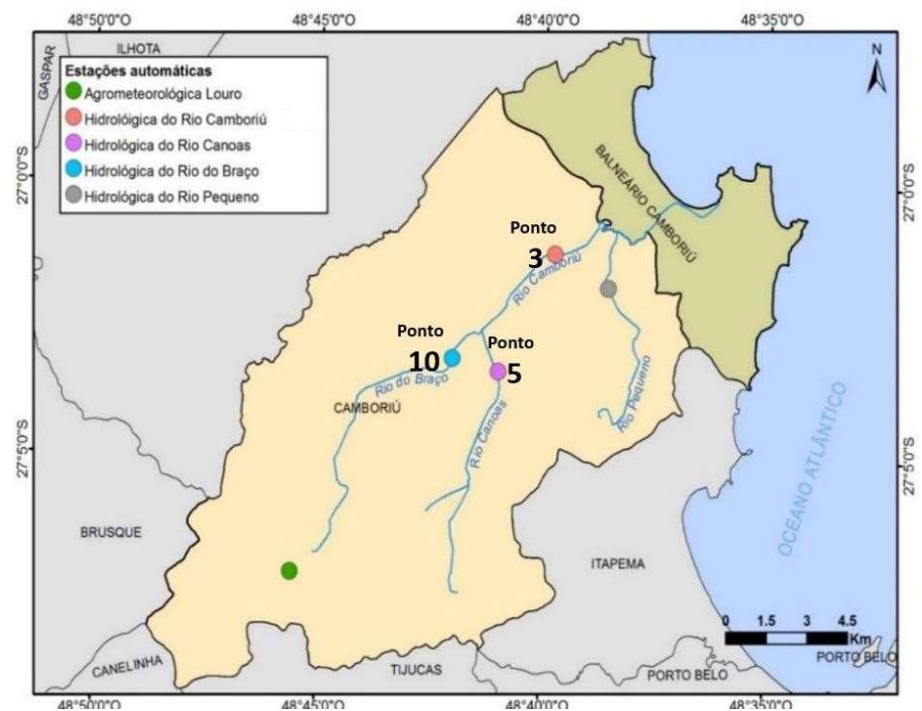

Figura 2: Localização geográfica dos pontos de coleta 3, 5 e 10 na Bacia Hidrográfica do Rio Camboriú (SC). Fonte: EPAGRI (2017)

O ponto 10 foi definido por sua importância no projeto PA, pois, foi a área piloto em 2013 (Região do Braço), local onde prepondera a rizicultura, portando faz-se necessário o estudo dos parâmetros químicos e biológico, o ponto 5 recebe água da Região dos Macacos, local onde o projeto PA iniciou em 2016. O ponto 3, recebe água das duas calhas principais da bacia e por ser o ponto onde está localizada a captação de água bruta. É importante mencionar sobre o ponto 3, que na década de 1990 foi construído próximo ao Ponto Captação de Água Bruta, no Rio Camboriú, uma barragem de nível no leito do rio, evitando durante a captação da água bruta a mistura da água doce com salobra. Os dados de Urban (2003) e EPAGRI (2017) foram coletados a montante deste ponto (barragem) e dados de Urban (2008), Silva (2015) e Rabelo (2018) foram coletadas a jusante (recebe influência efluente da Estação de Tratamento de Esgoto (ETE)). A distância geográfica entre os pontos a montante e jusante da barragem são de aproximadamente $580 \mathrm{~m}$ (SANTOS, 2018).

\section{RESULTADOS E DISCUSSÃO}

Segundo Molozzi et al. (2006) o monitoramento dos parâmetros de qualidade da água constitui em ferramenta importante, podendo ser usada para avaliar alterações ambientais oriundas das ações antrópicas. Os resultados que seguem podem indicar possíveis mudanças nos parâmetros físico-químicos e biológico da água na Bacia Hidrográfica do Rio Camboriú (BHRC) para o período de 2001-2017, associadas às áreas de intervenções do projeto Produtor de Água (PA). 


\section{Temperatura}

A temperatura dos corpos d’água apresentam variações de acordo com a sazonalidade e acompanham as flutuações do clima, influenciando os parâmetros: pH, condutividade elétrica, DBO, tensão superficial, viscosidade e oxigênio dissolvido. A análise dos dados demostrou que não há variações extremas para os períodos analisados, sendo registrada temperatura mínima de $11,9{ }^{\circ} \mathrm{C}$ para os pontos 3 e 5 em junho de 2016 e máxima de $29,6{ }^{\circ} \mathrm{C}$ para o ponto 3 em janeiro de 2015 (EPAGRI, 2017). Deve-se considerar que os pontos amostrais analisados estão em região potamal (baixa declividade e fluxo laminar) e sem proteção de mata ciliar.

\section{Oxigênio Dissolvido}

O oxigênio dissolvido (OD) indica água de boa qualidade quando seu valor for superior a $5 \mathrm{mg} / \mathrm{L}$ segundo a Resolução CONAMA N 357 (BRASIL, 2005). A análise dos dados registrou aumento de 6,38 mg/L para $6,84 \mathrm{mg} / \mathrm{L}$ a montante e de $4,69 \mathrm{mg} / \mathrm{L}$ para $6,03 \mathrm{mg} / \mathrm{L}$ a jusante para o ponto 3 (Figura 3), comparando valores antes e depois do projeto PA, podendo indicar ligeira melhora nas condições ambientais no local. Com relação ao ponto 5, foi observado aumento no período de 2001/2002 a 2005/2006, redução com relação à 2014/2015 e seguido de aumento quando comparados com 2015/2016 e 2014/2017 (Figura 3). O teste estatístico indicou diferenças significativas dos valores obtidos de diferentes autores para os pontos amostrais $3\left(P=10^{-7}\right)$ e $5(P=0,0018)$, porém, para o ponto $10(P=0,342)$ (Figura 3), apresentou similaridade. De modo geral, o OD apresentou indefinição na análise de melhoria ou piora da qualidade. Por outro lado, o fato do parâmetro não ter apresentado declínio na qualidade pode ser considerado como positivo, mesmo com frequentes relatos de degradação ambiental observados nos ecossistemas lóticos.

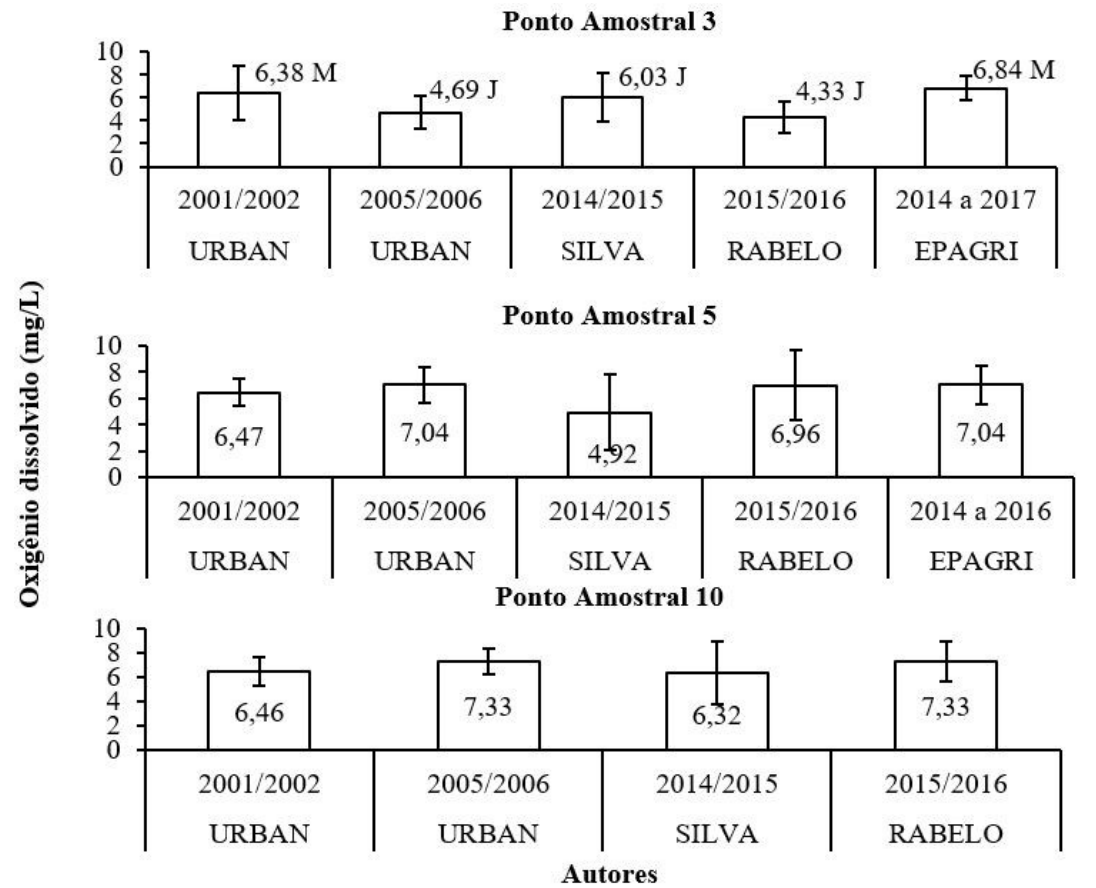

Figura 3: Oxigênio dissolvido [mg/L] nos pontos amostrais 3, 5 e 10 na Bacia Hidrográfica do Rio Camboriú (SC), para diferentes fontes de dados Urban, Silva, EPAGRI e Rabelo entre os anos de 2001 a 2017. Nota: média (coluna) com desvio padrão (barra); jusante (J) e montante (M) da captação de água bruta no Rio Camboriú. Fonte: Adaptado de EPAGRI (2017); URBAN (2008); SILVA (2015) e RABELO (2018) 


\section{Potencial Hidrogeniônico}

A análise dos dados de $\mathrm{pH}$ antes do projeto PA e depois projeto apresentam constância nos dados, sendo que o teste estatístico não mostrou diferenças significativas para os pontos $3(P=0,617), 5(P=0,603)$ e $10(P=0,136)$ (Figura 4). Contudo, no ponto 10 foi constatado um aumento de 6,57 para 7,48, que pode indicar atuação do projeto PA.

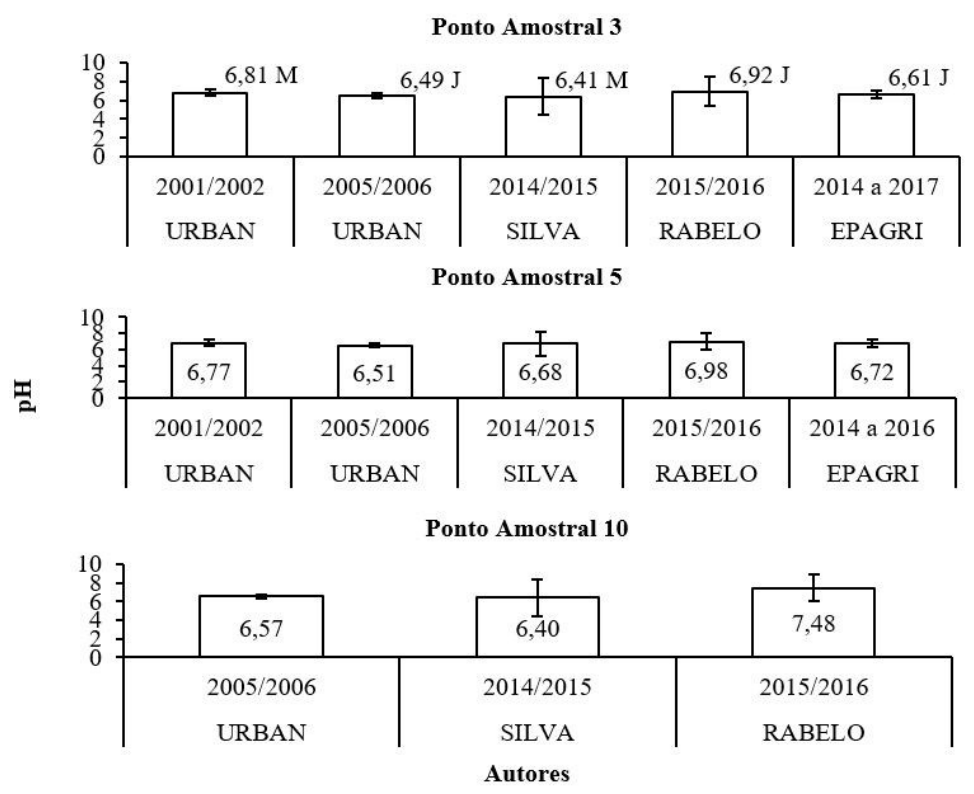

Figura 4: Potencial Hidrogeniônico $(\mathrm{pH})$ nos pontos amostrais 3, 5 e 10 na Bacia Hidrográfica do Rio Camboriú (SC) para diferentes fontes de dados Urban, Silva, EPAGRI e Rabelo entre os anos de 2001 a 2017. Nota: média (coluna) com desvio padrão (barra); jusante (J) e montante (M) da captação de água bruta no Rio Camboriú. Fonte: EPAGRI (2017); URBAN (2008); SILVA (2015) e RABELO (2018).

\section{Turbidez}
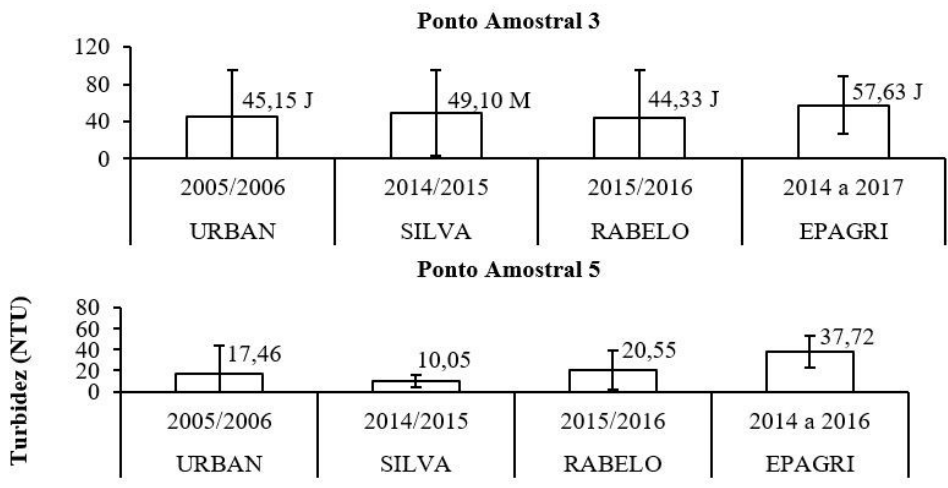

Ponto Amostral 10

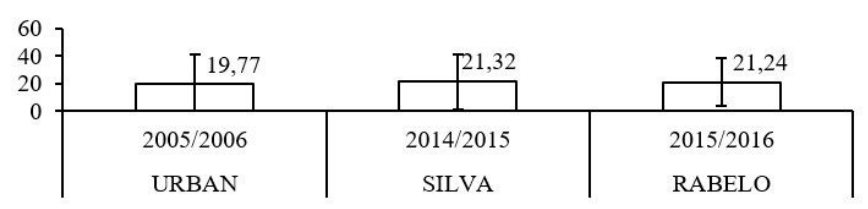

Autores

Figura 5: Turbidez [NTU] nos pontos amostrais 3, 5 e 10 na Bacia Hidrográfica do Rio Camboriú (SC) para diferentes fontes de dados Urban, Silva, EPAGRI e Rabelo, entre os anos de 2001 a 2017. Nota: média (coluna) com desvio padrão (barra); jusante (J) e montante (M) da captação de água bruta no Rio Camboriú. Fonte: Adaptado de EPAGRI (2017); URBAN (2008); SILVA (2015) e RABELO (2018).

Em geral, a análise estatística mostra um aumento da turbidez no ponto 5 ( $\mathrm{P}=0,000031)$ para período estudado, sendo observada similaridade nos pontos $3(P=0,708)$ e $10(P=0,976)$ (Figura 5). Valores 
altos da turbidez para os dados da EPAGRI podem estar associados ao fato que a coleta de dados foi realizada independente das condições de pluviosidade, as quais alteram a turbidez dos corpos d'água, sendo que os demais autores realizaram amostragens em dias não antecedidos por pluviosidades extremas. No ponto 10 , região de maior atuação do projeto PA, apresenta valores de turbidez estáveis ao longo do tempo (Figura 5). Este fato pode indicar que não houve piora das condições ambientais e sugere que o projeto PA pode estar impedindo o aumento da turbidez, o que não foi observado nos pontos 3 e 5 . Copper et al. (1987), afirma que cerca de 80 a 90\% da movimentação de sedimentos em áreas agrícolas são retidos pela mata ciliar, seu estudo comprovando a importância de sua preservação.

\section{Condutividade}

Os valores de condutividade nos pontos 5 e 10 apresentaram uniformidade (Figura 6). No caso do ponto 3 , a grande variação de condutividade para diferentes autores pode estar relacionada à posição do local de coleta, pois dados de 2005/2006 e 2014/2015 foram obtidos em ambiente que pode ter influência de água salobra.

O teste estatístico indicou similaridade entre os dados dos diferentes autores para o ponto 10 $(P=0,069)$ e diferenças significativas para os pontos $3(P=0,00054)$ e $5(P=0,0482)$. A região do Braço, onde se localiza o ponto 10, apresenta os menores valores de condutividade, apesar do cultivo de arroz irrigado na região, este fato pode ser explicado por dois fatores: atuação do projeto PA, conseguindo manter estável a condutividade na região e a redução da área de cultivo de arroz a partir de 2007, de 1.200ha para 950ha (IBGE, 2018). Os valores de condutividade relativamente altos podem ser explicados pelo uso de fertilizantes na rizicultura, este fato já foi comprovado nos estudos realizados por Conejo e Pereira Filho (2010) no rio Itajaí-Açu (SC), onde foi verificado um aumento da condutividade associada à deterioração da qualidade da água em função de seu uso na rizicultura irrigada.

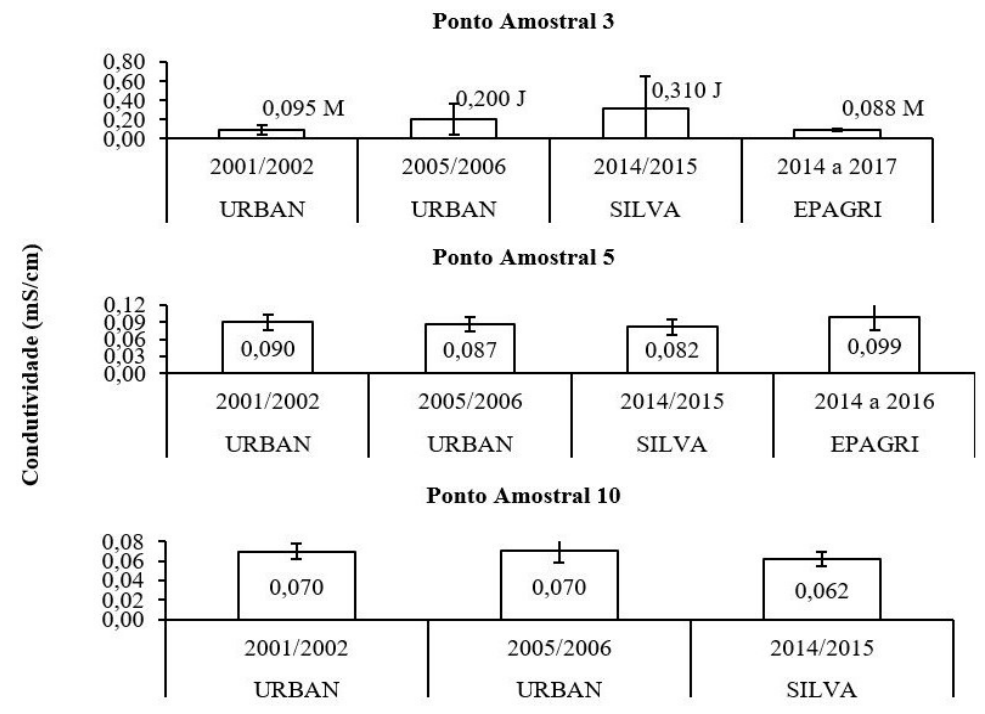

Figura 6. Condutividade $[\mathrm{mS} / \mathrm{cm}]$ nos pontos amostrais 3, 5 e 10 na Bacia Hidrográfica do Rio Camboriú (SC) para diferentes fontes de dados Urban, Silva e EPAGRI entre os anos de 2001 a 2017. Nota: média (coluna) com desvio padrão (barra); jusante (J) e montante (M) da captação de água bruta no Rio Camboriú. Fonte: Adaptado de EPAGRI (2017); URBAN (2008) e SILVA (2015). 


\section{Demanda Bioquímica de Oxigênio}

Os valores da Demanda Bioquímica de Oxigênio (DBO) para os pontos $3(P=0,845)$ e $5(P=0,0548)$ (Figura 7) apresentaram similaridade. Analisando os valores médios, observamos redução dos valores no ponto 3, entre $2001 / 2002$ e 2014/2015, o que pode indicar melhora no ambiente.

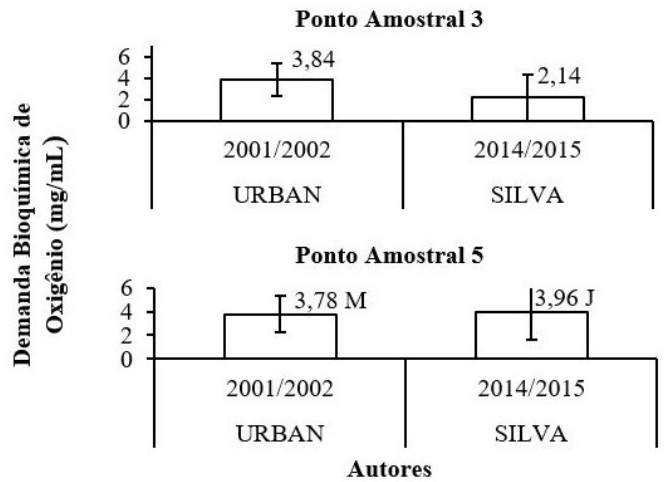

Figura 74: Demanda bioquímica de oxigênio, DBO [mg/L] para os pontos amostrais 3 e 5 na Bacia Hidrográfica do Rio Camboriú (SC) para diferentes fontes de dados, Urban e Silva entre os anos de 2001 a 2015. Nota: média (coluna) com desvio padrão (barra); jusante (J) e montante (M) da captação de água bruta no Rio Camboriú. Fonte: URBAN (2003) e SILVA (2015).

\section{Amônio}

Para o amônio foi verificado diferença significativa para o ponto $3(P=0,00039)$ nos períodos estudados, enquanto pontos $5(P=0,748)$ e $10(P=0,4354)$ apresentaram similaridade (Figura 8). $O$ amônio presente nos ambientes aquáticos possui diversas origens, dentre elas, a excreção dos organismos, a mineralização da matéria orgânica por bactérias heterotróficas e fontes externas como descargas de efluentes orgânicos e fertilizantes (RUSSO, 1985). No caso do ponto 3, o grande aumento do amônio no ponto 3 ao longo dos últimos 15 anos provavelmente está associado ao lançamento de esgoto urbano.
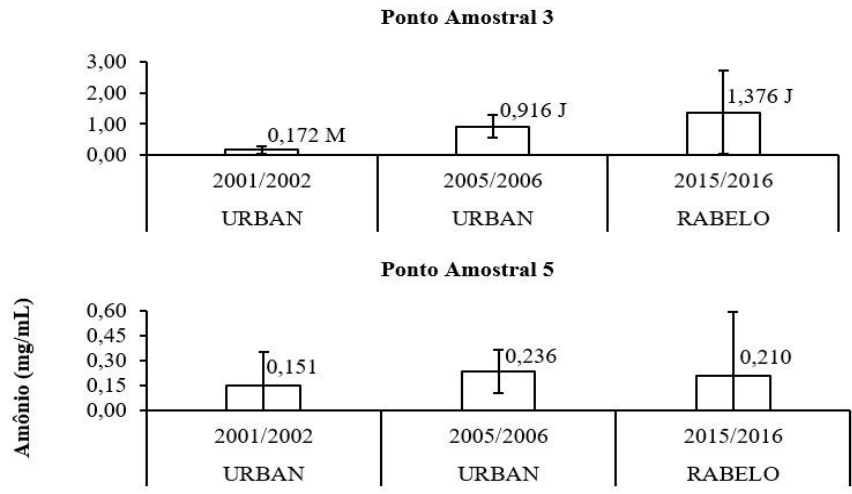

Ponto Amostral 10

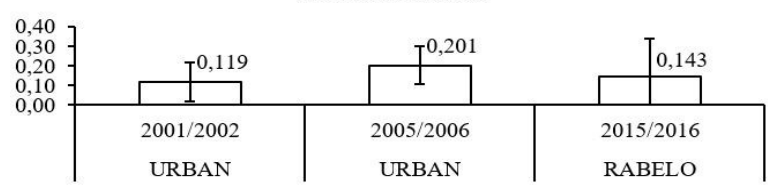

Autores

Figura 8: Amônio [mg/L] nos pontos amostrais 3, 5 e 10 na Bacia Hidrográfica do Rio Camboriú (SC) para diferentes fontes de dados Urban e Rabelo entre os anos de 2001 a 2015. Nota: média (coluna) com desvio padrão (barra); jusante (J) e montante (M) da captação de água bruta no Rio Camboriú. Fonte:

Adaptado de URBAN (2008) e RABELO (2018). 


\section{Nitrato}

Os resultados indicam diferenças significativas dos valores para os pontos $3(P=0,00039), 5$ $(P=0,0045)$ e $10(P=0,000018)$. Para o ponto 3, entre 2005/2006 e 2015/2016, foi registrada redução na concentração de nitrato à jusante do ponto de captação de água bruta no rio Camboriú. Nos pontos 5 e 10 foi observado comportamento similar, com aumento seguido de redução da concentração de nitrato (Figura 9). A redução mais expressiva observada, ponto 10 , pode ser resultado da atuação do projeto PA, mas também a redução da área da rizicultura em 2007 (IBGE, 2018).

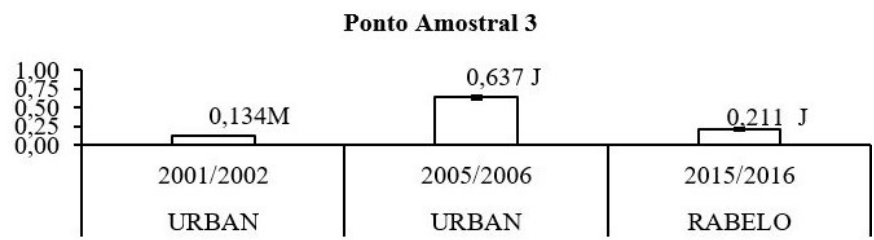

Ponto Amostral 5

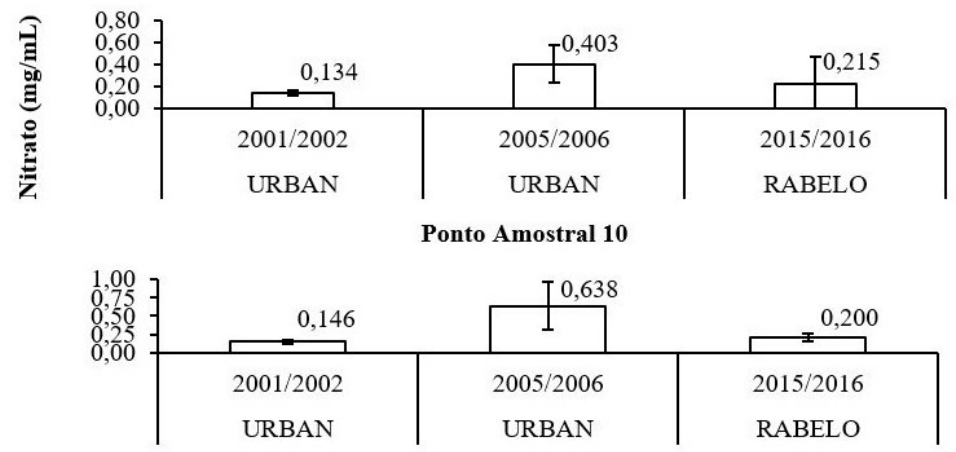

Autores

Figura 9: Nitrato [mg/L] nos pontos amostrais 3, 5 e 10 na Bacia Hidrográfica do Rio Camboriú (SC) para diferentes fontes de dados Urbano e Rabelo entre os anos de 2001 a 2016. Nota: média (coluna) com desvio padrão (barra); jusante (J) e montante (M) da captação de água bruta no Rio Camboriú. Fonte: Adaptado de URBAN (2008) e RABELO (2018).

\section{Nitrito}
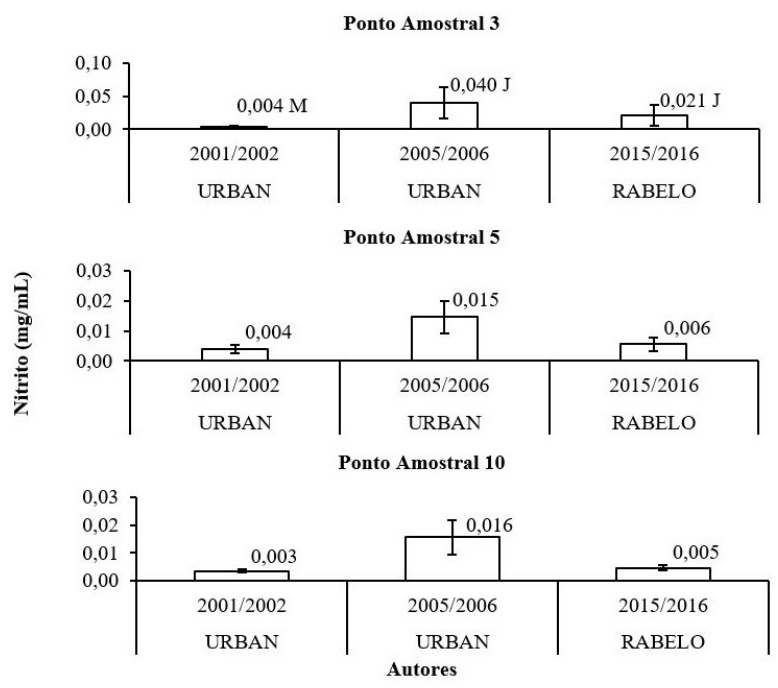

Figura 5: Nitrito [mg/L] no ponto amostral 3, 5 e 10, na Bacia Hidrográfica do Rio Camboriú (SC) para diferentes fontes de dados Urban e Rabelo entre os anos de 2001 a 2016. Nota: média (coluna) com desvio padrão (barra); jusante (J) e montante (M) da captação de água bruta no Rio Camboriú. Fonte: Adaptado de URBAN (2008) e RABELO (2018).

O teste estatístico indicou diferenças significativas entre os dados para os diferentes autores nos 
pontos $3(P=0,00049), 5\left(P=3 \times 10^{-7}\right)$ e $10\left(P=5 \times 10^{-8}\right)$. O ponto 3 apresentou redução da concentração no período de 2005/2006 a 2015/2016 a jusante, os pontos 5 e 10 indicaram aumento da concentração seguido de redução para os períodos de 2001/2002 a 2005/2006 e 2005/2006 a 2015/2016 (Figuras 10). Segundo Brigante et al. (2003), o composto nitrito é bastante solúvel em água, sendo um intermediário natural na oxidação microbiana do amônio para o nitrato. Por ser um estado intermediário entre amônio e nitrato, o aumento e redução da concentração acompanha a mesma lógica dos parâmetros, amônio e nitrato.

\section{Fosfato}

Diferenças significativas dos dados de fosfato para os pontos $3\left(P=4,2 \times 10^{-5}\right), 5(P=0,013)$ e $10(P=10$ 8). Foram observadas queda nos valores ao longo do tempo, especialmente entre 2005/2006 e 2015/2016. O suprimento de fósforo nos ambientes aquáticos regula a produtividade natural (Poli et al., 2004), sendo que as fontes deste elemento podem ser de origens naturais, através do intemperismo de rochas fosfatadas, mas também de origem antropogênica, decorrente de atividades agrícolas (fertilizantes) e pela poluição de Detergentes (Esteves 2011).

Estudos realizados na bacia hidrográfica do Rio Mogi-Guaçu também apresentaram aumento e redução da concentração fósforo entre 1989 e 1997 (Brigantes et al. 2003). Segundo Esteves (2011), o aporte de fosfato em rios acontece em maior parte por processos artificiais, como esgoto domésticos e industriais, processo que pode estar ocorrendo no ponto 3 do presente estudo.

Ponto Amostral 3

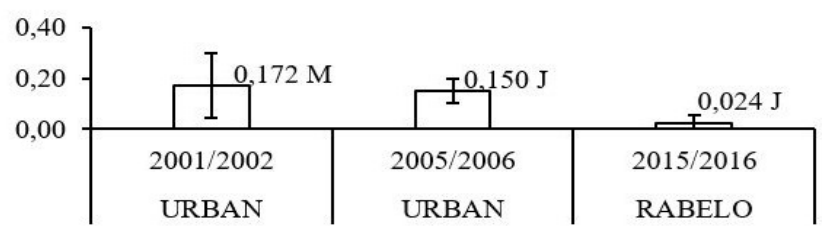

Ponto Amostral 5

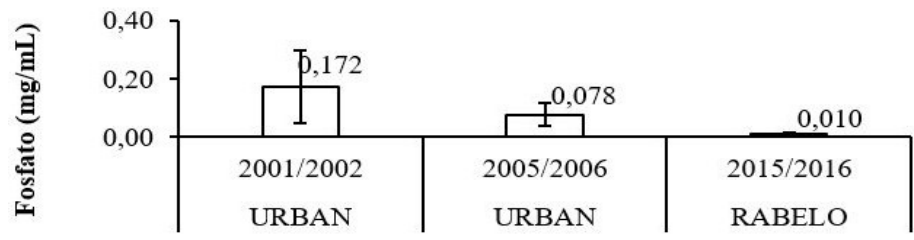

Ponto Amostral 10

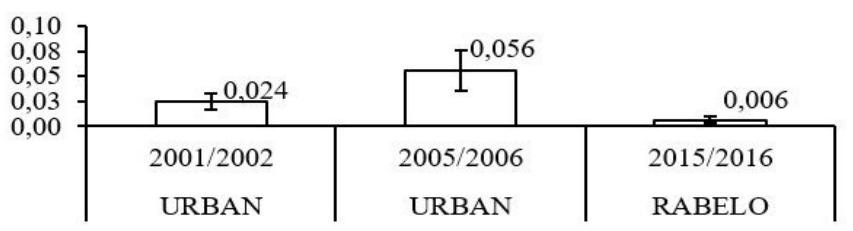

Autores

Figura 11: Fosfato [mg/L] nos pontos amostrais 3, 5 e 10 na Bacia Hidrográfica do Rio Camboriú (SC) para diferentes fontes de dados Urban e Rabelo entre os anos de 2001 a 2016. Nota: média (coluna) com desvio padrão (barra); jusante (J) e montante (M) da captação de água bruta no Rio Camboriú. Fonte: Adaptado de Urban $(2003,2008)$ e Rabelo (2018).

\section{Silício}

O silício apresentou similaridade nos dados para os três pontos amostrais $3(P=0,825), 5(P=0,585)$ 
e $10(P=0,316)$ (Figura 12). Foi registrado maior redução no ponto 10, aproximadamente $50 \%$. A queda nos valores de silício pode estar associada à redução da exploração de pedras no município de Camboriú, que segundo Zonta (2012) muitas pedreiras fecharam e a produção diminuiu nas últimas décadas.

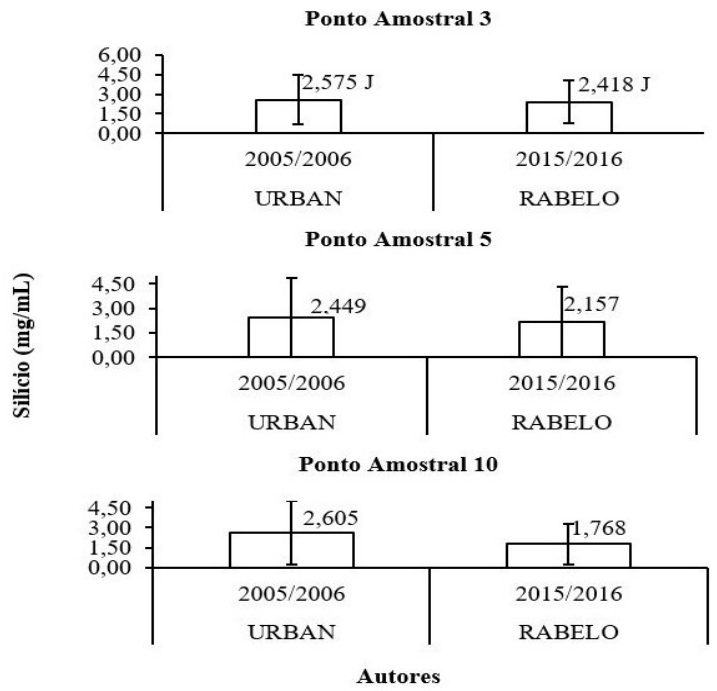

Figura 6: Silício [mg/L] nos pontos amostrais 3, 5 e 10 na Bacia Hidrográfica do Rio Camboriú (SC) para diferentes fontes de dados Urban e Rabelo entre os anos de 2005 a 2016. Nota: média (coluna) com desvio padrão (barra) e jusante (J) da captação de água bruta no Rio Camboriú. Fonte: URBAN

(2008) e RABELO (2018).

\section{Clorofila}

A clorofíla-a apresentou diferença significativa nos valores dos dados entre os pontos $3(P=0,02), 5$ $\left(P=6,4 \times 10^{-5}\right)$ e $10(P=0,011)$, demostrando redução de aproximadamente $50 \%$ (Figura 13). Entretanto, os maiores valores foram registrados no ponto 3 , provavelmente devido ao maior aporte de material orgânico, principalmente esgoto doméstico. A redução dos valores de clorofíla-a podem indicar melhor qualidade do curso d'água no período de 2005/2006 a 2015/2016, especialmente no ponto 10, área onde o projeto PA atuação há 5 anos, com ações que tem aumento da área de restauração e conservação.

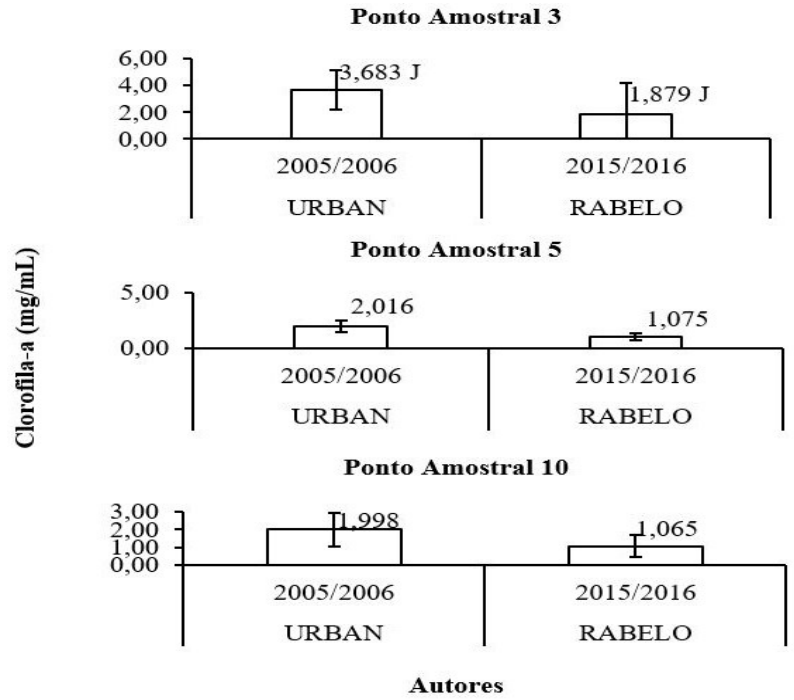

Figura 7: Clorofíla-a [ $\mu \mathrm{g} / \mathrm{L}]$ nos pontos amostrais 3, 5 e 10 na Bacia Hidrográfica do Rio Camboriú (SC) para diferentes fontes de dados Urban e Rabelo entre os anos de 2005 a 2016. Nota: média (coluna) com desvio padrão (barra); jusante (J) da captação de água bruta no Rio Camboriú. Fonte: URBAN (2008) e RABELO (2018). 


\section{Análise geral dos parâmetros físico-químicos-biológicos}

Com relação à qualidade da água da BHRC as análises, de modo geral, indicam estabilidade ou melhoria dos parâmetros analisados. Do total de análises realizadas para os pontos 3, 5, e 10 ( $n=35)$, foi observado melhoria na qualidade da água em $67,6 \%$ dos casos, sendo que $29,4 \%$ permaneceram constantes e apenas 3\% apresentaram declínio da qualidade. Por outro lado, o projeto Produtor de Água (PA) na BHRC, por ser recente, iniciou 2013, não permite afirmar que as melhorias apresentadas nos parâmetros são oriundas exclusivamente do projeto PA. Entretanto, os dados do ponto 10, em relação aos pontos 3 e 5, apresentaram os melhores resultados, que pode indicar atuação do projeto PA. Estudos a médio e longo prazo poderão confirmar ou não está tendência.

Avaliar o efeito do projeto PA na qualidade da água na BHRC é tarefa complexa, pois são várias situações que podem alterar a qualidade de um recurso hídrico. Large et al. (1996) afirmam que a reabilitação das matas ciliares promove o controle dos ciclos biogeoquímicos, restaurando a função natural, que é reter material particulado e absorver matéria orgânica, inorgânicas e poluentes, além de preservar e reabilitar a fauna e flora. Os principais rios da BHRC, em muitos trechos, encontram-se sem a proteção da mata ciliar, como o Ribeirão dos Macacos (Figura 14), favorecendo o carreamento de materiais orgânico e inorgânico para os corpos de água, diminuindo a qualidade do recurso hídrico e aumentando custo do tratamento da água.

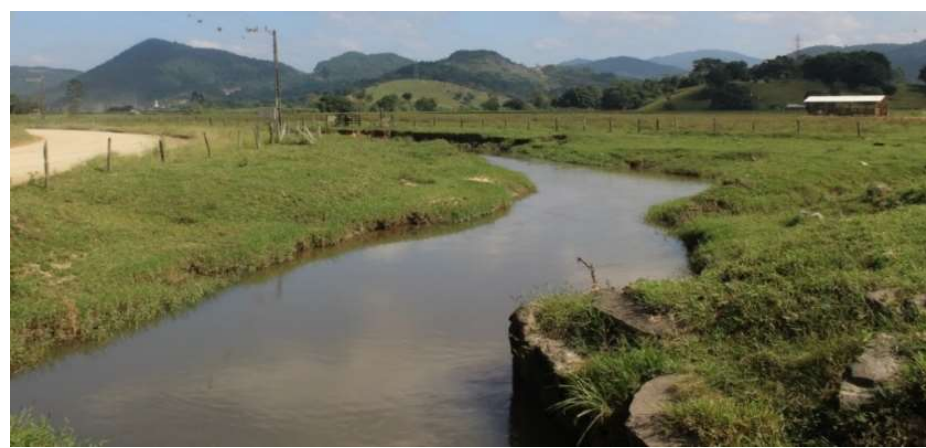

Figura 14: Ribeirão dos Macacos sem proteção da mata ciliar na Bacia Hidrográfica do Rio Camboriú-SC.

Estudos realizados no rio Mogi-Guaçu 2000/2001 apontam que um dos principais impactos na qualidade da água é a poluição orgânica, produto do lançamento de esgoto doméstico, associado ao aumento populacional naquela região (Brigante et al., 2003), o que ocorre também da BHRC. O Poder Público juntamente com a sociedade civil da Bacia Hidrográfica do Rio Mogi-Guaçu implementaram ações de curto-médio-longo prazos a fim de resolver a questão do poluição da bacia, como: recomposição e manejo de matas ciliares, plano de manejo de nascentes, sustentabilidade agrícola, orientações para os agricultores locais, novas formas de agricultura para a região, práticas de conservação de solos, captação de águas pluviais das estradas, saneamento básico, tratamento da água de consumo no meio rural e saneamento básico rural (BRIGANTE et al., 2003). O projeto PA da BHRC, apesar de implementar várias destas ações na bacia (SANTOS et al., 2017), necessita desenvolver intervenções mais eficazes para a melhoria da qualidade dos corpos de água, especialmente o saneamento básico. 


\section{CONCLUSÃO}

A Bacia Hidrográfica do Rio Camboriú é a menor bacia do Estado de Santa Catarina, onde o lançamento de poluentes como esgoto in natura, material particulado e nutrientes, comprometem a qualidade do recurso hídrico, aumentando o custo do tratamento da água. O projeto Produtor de Água (PA) pode estar contribuindo para melhorar ou manter a qualidade da água na bacia. Por ser recente, ainda não é possível afirmar que a melhoria da qualidade da água do recurso hídrico, a partir de 2013, esteja exclusivamente associada atuação do projeto. Entretanto, a região onde o projeto PA atua há mais tempo, apresenta resultados melhores para os parâmetros analisados quando comparados a outras regiões da bacia.

\section{REFERÊNCIAS}

ANA. Agência Nacional de Águas. Sobre a instituição. Brasília, 2018.

ANA. Agência Nacional de Águas Programa Produtor de Água. Brasília, 2012.

ANA. Agência Nacional de Águas. Manual Operativo. Programa Produtor de Água. Brasília, 2008.

ANTUNES, P. P.; CARVALHO, R. M.; ESPINOZA, H. C. F.. Análise da estrutura da paisagem da sub-bacia hidrográfica do Rio do Braço como subsídio para um projeto de pagamento por serviços ambientais no município de Camboriú, Santa Catarina, Brasil. Revista Sociedade \& Natureza, v.29, n.1, p.79-89, 2017.

ANTUNES, A.; SCHWINGEL, P. R.; BURLIGA, A. L. M.; URBAN, S.. Composição do fitoplâncton da bacia hidrográfica do rio Camboriú (SC, Brasil) durante o verão de 2005. Braz. J. Aquat. Sci. Technol., v.11; n.2, p.33-43, 2007.

BARBOSA, V.. A Última Gota. São Paulo: Planeta do Brasil, 2015.

BRASIL. Resolução Conama no 357. Dispõe sobre a classificação dos corpos de água e diretrizes ambientais para o seu enquadramento, bem como estabelece as condições e padrões de lançamento de efluentes, e dá outras providências. Brasília: DOU, 2005.

BRIGANTE, J.; ESPINDOLA, E. L. G.. Limnologia Fluvial: um estudo no Rio Mogi-Guaçu. São Carlos: Rima, 2003.

CONEJO, D. D. A.; PEREIRA FILHO, J.. Qualidade Química da água em função de seu uso na rizicultura irrigada na região do baixo estuário do Rio Itajaí. Revista de Estudos Ambientais, v.12, n.2, p.26-37, 2010.

COPPER, J. R.; GILLIAM, J. W.; DANIELS, R. B.; ROBARGE, W. P.. Riparian areas as filters for agriculture sediment. Soil Science Society of America Journal, v.51, p.416-420, 1987.

EPAGRI. Relatório Técnico. Florianópolis, 2017.
ESTEVES, F. A.. Fundamentos de Limnologia. Rio de Janeiro: Interciência, 2011.

IBGE. Instituto Brasileiro de Geografia e Estatística. IBGE Cidades. Brasília, 2018.

KLEMZ, C.; DACOL, K. C.; ZIMERMAN, P.; NAYARA J.; VEIGA, F.; DIEDERCHSEN, A.. Produtor de Água do Rio Camboriú. In: PAGIOLA, S.; GIEHN, H. C. V.; TAFFARELLO, D.

Experiências de Pagamento por serviços Ambientais do Brasil. São Paulo, 2013.

LARGE, A. R. G.; PETTS, G. E.. Historical channel-floodplain dynamics along the River Trent: implications for river rehabilitation. Applied Geography, v.16, n.3, p.191-209, 1996.

MMA. Pagamentos por Serviços Ambientais na Mata Atlântica: lições aprendidas e desafios. Brasília, 2011.

MOLOZZI, J.; PINHEIRO, A.; SILVA, M. R.. Qualidade da água em diferentes estádios de desenvolvimento do arroz irrigado. Pesquisa Agropecuária Brasileira, v.41, n.9, p.13931398, 2006.

POLI, C. R.; VINATÉIA, L.. Qualidade de água em aquicultura. In: POLI, C. R.; POLI, A. T. B.; ANDREATTA, E.; BELTRAME, E.. Aquicultura, Experiências Brasileiras. Florianópolis: Multitarefa Editora, 2004.

RUSSO, R. C.; GARY, M.; PETROCALLI, S. R.. Fundamentals of aquatic ecotoxicology: methods and aplications. São Paulo: Raud, 1985.

SANTOS, P. H.. Avaliação da Eficácia do Projeto Produtor de Água na Bacia Hidrográfica do Rio Camboriú (SC). Dissertação (Mestrado em Ciência e Tecnologia Ambiental) Universidade do Vale do Itajaí, Itajaí, 2018.

SANTOS, P. H.; SCHWINGEL, P. R.. Proposta para procedimentos de vistoria de projetos produtor de água: bacia hidrográfica do rio Camboriú - SC, Brasil. Brazilian Journal of Aquatic Science Technology, v.21; n.1, p.1-3, 
2017.

TUNDISI, J. G.; TUNDISI, T. M.. Limnologia. São Paulo: Oficina de Textos, 2008.
ZONTA, G.. Do broqueiro ao operário. Líder na extração de mármore e granito. Jornal Linha Popular, p.4-6, 2012.

A CBPC - Companhia Brasileira de Produção Científica (CNPJ: 11.221.422/0001-03) detém os direitos materiais desta publicação. Os direitos referem-se à publicação do trabalho em qualquer parte do mundo, incluindo os direitos às renovações, expansões e disseminações da contribuição, bem como outros direitos subsidiários. Todos os trabalhos publicados eletronicamente poderão posteriormente ser publicados em coletâneas impressas sob coordenação da Sustenere Publishing, da Companhia Brasileira de Produção Científica e seus parceiros autorizados. Os (as) autores (as) preservam os direitos autorais, mas não têm permissão para a publicação da contribuição em outro meio, impresso ou digital, em português ou em tradução. 